\title{
Perception of people with type 2 diabetes mellitus concerning an educational health process*
}

\author{
Percepção de pessoas com diabetes mellitus tipo 2 acerca de um processo de educação para \\ a saúde
}
Percepción de personas con Diabetes Mellitus tipo 2 sobre un proceso de educación para salud

\section{Aliny de Lima Santos ${ }^{1}$, Hellen Pollyanna Mantelo Cecilio ${ }^{2}$, Sonia Silva Marcon ${ }^{3}$}

Objective: to understand the perception of people with type 2 diabetes mellitus about the participation in an educational health process. Methods: qualitative study, conducted with 26 people with diabetes enrolled in the Association for Diabetics. There were 12 meetings entitled "reflective-educational process", based on the theoretical and methodological strategy of the Culture Circles. Meetings were recorded, transcribed and analyzed according to identification of generative themes and extreme situations. Results: two thematic units emerged: Being in group: space for embracement and construction of knowledge; and Realizing changes resulting from being in a group. Participatory meetings proved to be efficient, as they were configured as support network, space for motivation, construction of knowledge about the disease, living with it, and approximation between professionals and individuals. Conclusion: health education with participatory approach was perceived as satisfactory, favoring living with the disease and changing habits.

Descriptors: Diabetes Mellitus, Type 2; Health Promotion; Health Education; Nursing.

Objetivo: apreender a percepção de pessoas com diabetes mellitus tipo 2 acerca da participação em um processo de educação para a saúde. Métodos: investigação qualitativa, desenvolvida com 26 pessoas com diabetes cadastradas na Associação de Diabéticos: Realizaram-se 12 encontros intitulados "processo reflexivo-educativo", fundamentando-se na estratégica teóricometodológica dos Círculos de Cultura. Encontros gravados, transcritos e analisados segundo identificação de temas geradores e situações limite. Resultados: emergiram duas unidades temáticas: Estar em grupo: espaço de acolhimento e construção de conhecimento; e, Percebendo mudanças decorrentes do estar em grupo. Os encontros participativos mostraram-se eficiente, à medida que se configuraram como rede de apoio, espaço de motivação, construção de conhecimento sobre a doença, convivência com ela, e aproximação entre profissionais e indivíduos. Conclusão: a educação em saúde com abordagem participativa foi percebida como satisfatória, favorecendo a convivência com a doença e a mudança de hábitos.

Descritores: Diabetes Mellitus Tipo 2; Promoção da Saúde; Educação em Saúde; Enfermagem.

Objetivo: aprehender la percepción de personas con Diabetes Mellitus tipo 2 sobre la participación en un proceso educativo para salud. Métodos: investigación cualitativa, desarrollada con 26 personas con diabetes, registradas en Asociación de Diabéticos. Hubo 12 reuniones intituladas "proceso reflejo-educativo", basándose en la estrategia teórica y metodológica de los Círculos de Cultura. Reuniones grabadas, transcritas y analizadas según identificación de temas generadores y situaciones extremas. Resultados: surgieron dos unidades temáticas: Estar en grupo: el espacio de acogida y construcción del conocimiento; y Percibiéndose cambios resultantes de estar en grupo. Reuniones participativas demostraron ser eficientes, ya que se configuraron como soporte de red, espacio de motivación, construcción del conocimiento sobre la enfermedad, convivencia con ella, y aproximación entre profesionales e individuos. Conclusión: educación para salud con enfoque participativo se percibe como satisfactoria, lo que favorece el convivio con la enfermedad y el cambio de hábitos.

Descriptores: Diabetes Mellitus Tipo 2; Promoción de la Salud; Educación en Salud; Enfermería.

\footnotetext{
*Article originated from the dissertation: “Educação para a saúde de diabéticos através dos círculos de cultura: uma estratégia de intervenção em enfermagem", Universidade Estadual de Maringá, 2011.

${ }^{1}$ Universidade da Integração Internacional da Lusofonia Afro-Brasileira. Fortaleza, CE, Brazil.

${ }^{2}$ Universidade Estadual do Rio de Janeiro. Rio de Janeiro, RJ, Brazil.

${ }^{3}$ Universidade Estadual de Maringá. Maringá, PR, Brazil.

Corresponding author: Aliny de Lima Santos

Rua Casemiro de Abreu, 460, Bloco A apto 306. CEP: 60710-250. Fortaleza, CE, Brazil. E-mail: aliny.lima.santos@gmail.com
} 


\section{Introduction}

The diagnosis of type 2 diabetes mellitus brings a new routine and, therefore, living with diabetes mellitus type 2 implies changes in lifestyle, in eating habits, adaptation to routines, implementation of care and blood glucose control procedures, aiming to prevent acute and chronic complications for a healthy living ${ }^{(1)}$. Thus, promoting the acceptance and good living with the disease constitutes a priority for the health system, especially by enhancing knowledge about the disease ${ }^{(2)}$.

Thus, the efficient management of the disease can be facilitated through educational activities that enhance empowerment of patients and of the people with whom they live. Therefore, it is essential to provide access to information and guidelines for supporting the development of knowledge to drug therapy, skills and attitudes needed for a consciously and autonomous self-care ${ }^{(3-4)}$. Nevertheless, health education has been identified as one of the key devices to enable health promotion in primary care in Brazill ${ }^{(4)}$, and is even more effective when based on dialogue and the exchange of scientific and popular knowledge, which helps people to participate actively in the health-disease process ${ }^{(5)}$.

When it comes to nursing, care mediated by health education is in evidence, as it is now recognized as a promising strategy in dealing with multiple health problems ${ }^{(5)}$. Health education is in the context of nursing practice with a view to establishing a dialogical-reflexive relationship between nurse and client, in which the clients seek to become aware about their health-disease situation and perceive themselves as subjects of transformation of their own life ${ }^{(6)}$.

However, this approach is not always used to favor dialogue and collective participation. In everyday practice, it is observed that although nurses working in primary care of eight municipalities of the state of Paraná acknowledge the importance of carrying out health education and develop educational activities constantly in their work among the population, they maintain these actions focused on disease and on transmitting information only when the user seeks the service, often when the disease is in its advanced course $^{(3)}$. It is stressed the need to implement different approaches to health education, especially by nursing professionals, such as those working more directly with individuals ${ }^{(3)}$.

During educational practices with a view to selfcare in type 2 diabetes, the individual must participate in decisions, and it is necessary to consider, among other aspects, the level of knowledge, self-efficacy and motivation to treatment adherence ${ }^{(7)}$. Thus, knowledge of the person with type 2 diabetes about the disease and the factors involved in its control and proper management are critical to self-control of the disease $^{(2)}$.

However, in the routine of health services, especially in primary care, educational activities are carried out through collective practices and lectures, in order to provide information about the disease. These often have diminished participation of users ${ }^{(4)}$, ignoring their experience, culture and beliefs about the disease and adaptations used by them ${ }^{(3,5)}$.

When based on dialogue and group discussions, educational approaches have greater social impact because they allow the active participation of individuals who have in common the situation of living with the same disease. In addition, they favor the understanding of the social dimension and the difficulties encountered and the collective search for answers to latent questions that often only emerge in the interaction between people with similar experiences $^{(8)}$.

Thus, in health practices, the questioning and dialogue constitute ways to contribute to the health promotion strategy, which requires from professionals the ability to work under this approach and to rethink the information transference practices on the disease and behavior prescription, opening up to the possibility of mutual sharing of knowledge ${ }^{(9)}$. In this sense, health education in a participatory manner, 
appears as a dynamic learning space and knowledge exchange between its participants, allowing the participant subject to intervene in reality ${ }^{(10)}$. Given the above, the purpose of the study was to understand the perception of people with type 2 diabetes mellitus about the participation in an educational health process.

\section{Method}

This is a descriptive study of qualitative nature and participatory approach, developed with people with type 2 diabetes enrolled in the Association of Diabetics of Maringa, Parana, Brazil.

To conduct the study and collect information, the Culture Circles, proposed by Paulo Freire, was adopted as a methodological strategy during 12 meetings called "educational-reflexive process". This approach, also known as "Research Itinerary", consists of distinct stages that are interrelated in construction movements that go forward or retroactively, as required ${ }^{(10)}$. Moreover, it proposes the conduction of an educational process focused on the joint construction of knowledge through a dynamic learning space for exchange of experiences. In this process, educators and learners have knowledge and are able both to offer and to receive information ${ }^{(11)}$.

The reflection resulting from this collective approach allows decoding, recognition of problems and search for appropriate solutions, always through the group construction ${ }^{(10)}$. This educational proposal is able to provide to those who participate in it the opportunity to become active agents of change, to develop the ability to observe reality, to reflect on it and to seek possible ways to modify it ${ }^{(12)}$.

Meetings were held weekly in the Association, from May to July 2011, with an average duration of 90 minutes each. As for the inclusion criteria, people with type 2 diabetes, over 18 years old, of both genders, were invited to attend meetings. The invitation to participate in the groups was disseminated through posters set out in the Association and through telephone contacts with the people registered. Upon requesting participants and with permission of all, the meetings were fully recorded with the use of digital device.

In the performance of each of the 12 meetings, three stages were considered: 1 . Thematic Research and Survey of Generating Themes; 2. Encoding and Decoding of Generating Themes and 3. Critical Unveiling of Issues $^{(11)}$.

In the first moment, the generating themes were identified from the development of workshops involving activities such as writing, painting, collage and drawing, which allowed participants to express the topics of greatest interest, reflect on them and verbally express the feelings involved in this process. Aspects manifested by each participant were recorded by the facilitators and the end of the activities they were exposed to the group in order to validate their relevance. In the second moment, encoding and decoding of generating themes, participants could also add other aspects they considered relevant, so that topics and generating words were encoded and decoded; seeking to raise awareness and identification of extreme situations and their meaning for participants ${ }^{(11)}$.

The third and final moment, the critic unveiling, consisted of awareness of the problems faced and experiential situation with the recognition and discussion of the limits, difficulties and possibilities before reality. From this, issues previously mentioned were discussed, to identify possible solutions ${ }^{(11)}$.

The treatment of data began with the verbatim transcription of the meetings, fluctuating readings and detailed readings of the entire transcript content until extreme situations that permeate living with diabetes and generating themes were identified in order to obtain the aggregation of data and the transformation of them into text understanding cores, by similarity of themes/subjects. Finally, there was a deepening of the readings and identification of thematic units, considering the research objectives, the themes that emerged during the collection and analysis of data 
and theoretical assumptions ${ }^{(10)}$.

During the 12 meetings of the group, the reports of participants showed the extreme situations, themes and generating words, reflecting the perceptions related to participation in the culture circles, allowing to classify them into two thematic units: Being in group: space for embracement and construction of knowledge; and Realizing changes resulting from being in a group.

The development of the study followed the ethical precepts recommended by Resolution 196/96 of the National Health Council and approved by the Standing Ethics Committee of Research with Human Beings of the State University of Maringa (Opinion 148/2011). All participants signed two copies of the Informed Consent Form and, to ensure their anonymity, they were identified with the letter P (participant), followed by an identification number and the letters $\mathrm{M}$ or $\mathrm{F}$, indicating male and female (eg P1F).

\section{Results}

Of the 26 people with type 2 diabetes, nine were women and 17 were men. Women had age ranging from 38 to 64 years old and participated in two to seven meetings. Men were aged from 42 to 83 years old and participated in one to nine meetings. The monthly income varied from two to four minimum wages and their families consisted of two to five members, but one of the participants lived alone. Among them, 15 were married, six were divorced, three were widow(er)s and two were singles. The time of living/diagnosis of the disease ranged from four months to 19 years; and 19 participants were treated with oral anti-diabetic drugs and seven associated the use of insulin.

In the course of the 12 meetings, the reports translated the perceptions of participation in the educational group for health, which allowed classifying these perceptions into two categories: Being in group: space for embracement and construction of knowledge, and realizing changes resulting from being in group.

\section{Being in group: space for embracement and construction of knowledge}

Individuals revealed feeling satisfied with the way the circles had been conducted, as they received opportunity to express their ideas and concerns, and also to discuss, jointly, the problems experienced: I like when people explain things about diabetes. But the way we do here in the meeting, I think it is even better. Because it's different, isn't it? We don't just listen, we talk also discuss together and each one has their space to say what they think about the issues (P4M). Here, we listen about the problems of others and wonder:-My problem is not that big! We always go to lectures, but I do not like to go there because it is all about listening the doctor or the nurse, telling us to take the medicine on time, which is good for controlling diabetes. They do not know me, nor listen to me (P22F).

The reports show important aspects related to the annoyance with the dictates and prescriptions of behavior and habits by health professionals. That is why they value the fact that they can talk and, upon learning of the problems experienced by others, minimize their problems. However, they proved to be sad with the approach of some professionals regarding treatment adherence, who often associate the uncontrolled blood glucose with improper adherence to guidelines: The more we go to the doctor, the worse we stay. We feel bad having to do only what he says. My doctor prescribed a medicine for diabetes and a diet, but it did not work, then he kept changing and changing the medicine but nothing worked. He ended up saying that it was me who was not doing what he told. That's why I like to come here! Here I am heard, I feel good, I can talk, tell my problems and I always leave wanting to improve and come back next week telling changes (P6M). I started going to a nutritionist who prescribed a diet, but every time I went there, I had gain more weight, so she said the only explanation is that I was doing something wrong. It was not working out anyway, so I stopped seeing her. I started to follow my diet the way I thought it should be. I started coming to the meetings, and I feel much better. I know that only being here will not change my illness, but I talk, I listen, and it helps me to have the will to change, to have strength (P13M).

The encouragement perceived by participating in the group can be seen through the report and shared 
experiences that allow making knowledge property of all and for all, expanding the conditions for a more peaceful coexistence with the disease: When I found out I was diabetic, I knew nothing about the disease, so I went to the doctor and he sort of explained to me, he said everything I could and could not eat, he gave me a little list, and gave me medicine. I returned to home desperate! And now? Will I die? Will my leg be amputated? I still do not know exactly how this disease works, but by coming here, I've learned quite a lot. Look, now I understand much better than before (P25F).

Thus, the interaction with others who have the same experiences and difficulties motivates people to strive for change and for a better quality of life: As in her case (referring to $\mathrm{P} 17 \mathrm{~F}$ ), she came here and said she refused to accept she had diabetes, that she did not tell anyone, not to have anyone controlling her eatinghabits. People come here and it seems that they feel free to talk, to vent without fear of recrimination. I think that way, when we talk, when we really accept it, it is easier to change (P12M). Someday I'll be here telling that I managed to be like P8M, who can be controlled in the food without problems, that I went dancing. I come here and I see him talking and it seems so easy. If he can, if he can, I can, also (laughs) (P19M).

\section{Realizing changes resulting from being in group}

The testimony of the same person at the beginning and after some participation in meetings demonstrates the changes resulting mainly from a better acceptance of the disease: It's not easy being a diabetic, I cannot eat what I like; it's all about controlling things, food. This is not life! (P16M - first participation). At first, I used to be very irritated with this disease, it seems I did not accept it, you know? It seems that now I do not see that way anymore. I started to see that I still have a lot to do, that this disease is not the end of the world. I feel much better now, even the relationship with my family has improved (P16M - seventh participation).

One of the participants revealed that formerly she had hidden the disease from her family for fear of imposition and interference in her eating habits and then she told about the disease, as she recognized that family members can be important allies: I never told my family that I have diabetes. This disease is mine, I do not feel like telling anyone, because if I tell, they will say what I can and cannot eat. I'm too old to receive orders from children and husband (P17F - first participation). After I told my husband and my children I have diabetes, they always complain about my food (laughs), but it is good because I started to eat better, not to mention that my husband surprised me by getting all attentive and concerned about me. Even when I sneeze, he gets worried (P17F - fourth participation).

Another participant, in turn, showed that the biggest change was her relationship with food and, in a way, being committed to the group was the main supporter of changes: When I think about the candies I get crazy, not to mention pasta, so I go there and eat it, I don't even care. If I die, at least I die happy for having eat what I wanted (P4F - first participation). I want to tell something to you: today I went to the market, but I skipped that section of candies, the same that I could not resist. I kept looking each candy more delicious than the other. But I did not buy, guys (laughs) I remembered you and I did not buy (P4F - fifth participation).

As for this participant, the aspect that has come to be valued was checking the blood glucose: I don't like to check (referring to checking blood glucose), I think when we do the tests, we start to get paranoid and angry with blood sugar levels that never decreases. It does not hurt; I don't feel anything, so for me it's okay. I already know the levels are high, anyway (P26M - first participation). I am measuring three to four times a week to see if it is high. I eat things more carefully and I'm always attentive. It's great to see that even when I eat the little things I like, in moderation, when I do the test, I see it is okay. Performing the tests periodically is really a good idea (P26M - sixth participation).

\section{Discussion}

The reports allow us to infer that the participation in the group was valued by the subjects, and even with small changes in self-management of the disease, it was realized that they were satisfactory for everyone, regardless of the time of diagnosis and the way of living with the disease they had. All participants was considered autonomous subjects, full of knowledge and experiences to share, and with potential to manage their own change and at the same time able to inspire changes in others, which has 
motivated them to change and better acceptance of the disease ${ }^{(8)}$.

This type of relationship favored communication, satisfaction and changes from the participants, particularly concerning eating habits, which are now better adapted to the condition of each. It should be noted that many changes were reported in the group, and in these moments it was possible to see their pride resulting from overcoming obstacles. It also became evident how much the participants valued the opportunity to exchange experiences, to report achievements and how these opportunities were encouraging and provided examples to be followed.

Thus, it is understood that the health promotion, held through educational activities with participatory approach as a strategy in the treatment and management of diabetes, needs to be increasingly valued and used by health professionals from various fields. These should equip people with information about the disease and how to monitor it, in addition to encouraging the adoption of healthy habits, which improves the quality of life and increases the autonomy of the individual against the disease ${ }^{(12)}$.

Promoting health education activities among people with type 2 diabetes can have a key role in the encouragement and support so that they can take responsibility for the control and acceptance of the disease and its treatment ${ }^{(13)}$. Positive effects of the educational process in diabetes have been identified in various parts of the world ${ }^{(14)}$, which shows that, upon receiving effective treatment, support and encouragement of self-management and regular follow-up, people present improvement in glycemic control, prevention and control of acute and chronic complications.

Thus, improvement of the conceptual notions, especially on the definition of the disease, its symptoms, complications and important behavioral factors for its control are perceived in individuals who experience education-based health interventions for people with diabetes $^{(7)}$. In addition, health education activities can be developed in groups and individually, fostering a closer relationship between health professionals and patients $^{(15)}$. When in a group, the benefits of health education actions are even greater ${ }^{(4,9)}$, because, in general, participants refer pleased to be able to share experiences with those who understand the problem from their own experience ${ }^{(15)}$.

Moreover, the results of this study show that "being in group" favored the socialization and the collective construction of knowledge about type 2 diabetes and the possible ways of living with it. This is because, at the same time, individuals have the opportunity to report their experience with the disease, they identify and recognize in the experience of others their own experience, and they also can learn different ways to face it, developing, jointly, strategies for treatment ${ }^{(10)}$.

Research also suggests this alternative and conclude that education in self-care facilitates the knowledge and skills related to healthy practices to improve metabolic control and preserve or improve the quality of life at reasonable costs ${ }^{(10,15)}$. The American standardization of Diabetes SelfManagement Education points out the importance of the educational process based on the educational needs of the population considering the medical history of the individual, age, cultural influence, beliefs and health attitudes, knowledge about diabetes, willingness to learn, level of education, family support and financial status ${ }^{(16)}$.

In turn, the dialogic and participatory approach replaces the model of knowledge transference, in which health education practice puts patients in the role of "learners" or "listeners", merely. This approach goes beyond, and authors chose to develop it due to the desire to give rise to a participatory experience with emphasis on dialogue, leading to reflection-action in the collective elaboration of ways to better live with type 2 diabetes ${ }^{(11)}$. The greatest quality perceived in this group was the demonstration/participation of most individuals at all times of dialogue, which validated the practice because they sought to extrapolate individual learning, also producing their 
own and renewed, solidarity and collective ways of experiencing diabetes.

So, when professionals do not recognize the educational practice as a space for collective growth through knowledge built from the exchange of experiences, this practice remains unattractive and not adapted to the reality of participants ${ }^{(13)}$. This was observed in the participants' testimonies when they referred to the lectures they used to participate, characterizing them as unsatisfactory and nonspecific. The talks, in general, besides not stimulating the effective participation of individuals, provide ready information, which are presented in imposing form, prescribing attitudes and habits not consistent with the real needs and availability of participants ${ }^{(4-5)}$.

In short, the lack of knowledge about the disease both of caregivers and of the individuals themselves, combined with inadequate training and integration among health professionals, is directly related to the problem of adherence to healthy practices and treatment ${ }^{(8)}$. These findings indicate the ineffectiveness of traditional strategies, being necessary to incorporate in the health services new approaches that motivate people with type 2 diabetes, causing to raise awareness about the adoption of new habits and lifestyle, educating them about the risk the disease can bring if not controlled ${ }^{(7)}$.

An example of this reality can be seen in a study with 52 health care professionals working in primary care, aimed to know their views about the term "health education". Although at times professionals recognized that the user should be a participant in the educational process, in general there was prevalence of the understanding that they should simply pass on information because this strategy reduces risk of the approach and content are not understood by the user $^{(17) .}$

The traditional teaching approach becomes ingrained from the health professionals training, especially for nurses, resulting in its perpetuation as the only approach available in educational practices experienced in everyday life of these professionals. This approach, in turn, results in impositions of health behaviors that are not compatible with expectations and interests of the community ${ }^{(9)}$. Nevertheless, most health professionals recognize the lecture as the most appropriate methodology and that best characterizes health education, aimed at users who are understood as those who maintain inadequate lifestyles that need to be corrected ${ }^{(1,17)}$.

Through participatory education, it becomes possible to minimize thisgap, basing on the reflection of the participants' reality, deciphering and transforming $\mathrm{it}^{(11)}$. In the meetings conducted by us, disease coping aimed at the reality of each participant, their values, knowledge and specificities was valued at all meetings. In this sense, we understand that the purpose of health education is to enable people to remain healthy from access to information and opportunities that enable them to make choices toward a healthier life ${ }^{(13,18)}$. The absence of a more effective communication between healthcare professionals and people with diabetes interferes in an improved health care ${ }^{(1)}$.

This fact can be seen when participants reported that despite following the guidelines properly, they fail to maintain controlled glucose levels, and for this reason they were considered nonadherent and disobedient. This highlights the gap in communication between patients and professionals, which further discourages treatment adherence to for the disease because the patient with diabetes does not feel appreciated in their effort to change certain habits ${ }^{(13,19)}$.

Reports of some participants show that the imposition of health professionals is perceived negatively by patients, and the most serious aspect is that this kind of relationship with health professionals, rather than promote treatment adherence, leads individuals to ignore the guidelines received. In contrast, they felt welcomed, understood, encouraged and respected when participating in groups promoted this study. By performing health education, 
referencing the culture circle, it was possible to equip the subjects to recognize their potential for self-care, to accept the disease and to deal with it through their own resources ${ }^{(1,10)}$.

It was also evident that the non-monitoring of blood glucose levels is as a way to escape the problem, denying the possibility of aggravation of the disease and to mask the lack of adherence to treatment. It was observed that there was a change in attitudes and better awareness of the importance of proper eating habits and better monitoring of blood glucose levels to control the disease. Furthermore, seeing controlled levels during verification was perceived as a reward for the efforts made to control eating habits.

Moreover, it was observed that the approach through educational workshops used in this study was efficient and favored the participation of all, since it raised discussions according to the demand of those participating. Enhancing the recreational activities and socialization of groups such as self-esteem promotion strategy, fostering communication and the establishment of social relations, valuing cultural activities and creating opportunities for moments of relaxation and joy encourage the participation of individuals and transform the group into a moment to express their feelings, fears, and whether or not related to the disease doubts, more openly ${ }^{(9)}$. Similar results were observed in integrative review ${ }^{(20)}$ that sought to make an overview of approaches to promote educational strategies for people with type 2 diabetes.

The findings of this review $^{(20)}$ indicate that workshops have gained ground in the health education studies because of their positive impact among participants, and are considered a pedagogical strategy easy to understand, interactive, fun and motivating, besides encouraging discussion of the challenges and difficulties in structuring the education practice on diabetes. It was also concluded that performing educational meetings allows more significant changes in lifestyle, contributing to the promotion of health and wellbeing.
It should be noted that based on the statements, several valid aspects were identified through participation in the educational process, such as the recognition of the difficulties and the possibility of overcoming, the recognition of the group as a space for freedom of expression and sharing and the inspiration through the achievements of others, so as to pursue their own.

Coping with a chronic disease, particularly type 2 diabetes, implies significant changes in a person's life, not only due to the deleterious effects of the disease itself, but also due to glycemic control measurements, diet, performance of physical activity and possible changes in emotional status. Participants revealed that they felt welcomed and understood within their diabetic universe and not simply directed to a pre-dictated behavior. They also recognized that the information was not passed on, but built with the participation of all.

Another important aspect to be considered is that when the individual feels belonging to a group and committed to it, they make changes in their life and overcome obstacles, and perceive this group as a support network as they meet people experiencing problems similar, or worse, to theirs (17). Thus, it is necessary that some professionals review their concepts of health education, not to use it only as a moment of information transference.

For nursing, this study is extremely valuable, because it shows that although the transference of concepts and information is necessary, it should not be imposing nor occur vertically, but through an exchange of experience and joint construction of new knowledge. This fact imposes the need to reflect on professional practice in the educational field and to create mechanisms to overcome the health education model adopted hegemonically in health services in different parts of the country, linking diabetes to food restriction and prescription of lifestyle habits little adapted to patients' reality. 


\section{Conclusion}

Health education using participatory groups approach was effective for the improvement of living with the disease through awareness of individuals with consequent change of habits. It is believed that changes such as improve in self-management, acceptance of the disease and the development of responsibility for health were closely related to the autonomy reached from the educational activity and constructed joint and in a participatory manner.

We highlight the need for further studies using this approach in the development of educational activities, with participation of other health professionals, in order to promote the practice of "listening to the subject", starting to better recognize their real needs.

\section{Acknowledgements}

To the Coordination of Higher Education Personnel Training for the scholarship granted during the Masters, which gave rise to this study.

\section{Collaborations}

Santos AL and Cecilio HPM contributed to the study design, analysis, data interpretation, article writing and final approval of the version to be published. Marcon SS contributed to study design, data interpretation, article writing and final approval of the version to be published.

\section{References}

1. Tavares BC, Barreto FA, Lodetti ML, Silva DMGV, Lessmann JC. Resiliência de pessoas com diabetes mellitus. Texto Contexto Enferm. 2011; 20(4):7517.
2. Silva DAR, Lutkmeier R, Moraes MA, Souza EN. Knowledge about diabetes in patients hospitalized for heart disease: a descriptive research. On line Braz J Nurs [Internet]. 2013 [cited 2014 may 20];12(2):143-8. Available from: http://www. objnursing.uff.br/index.php/nursing/article/ view/3876

3. Roecker S, Marcon SS. Educación en salud: Relatos de las vivencias de enfermeiros com la estratégia de salud familiar. Investig Educ Enferm. 2011; 29(3):381-90.

4. Torres HC, Pereira FRL, Alexandre LR. Evaluation of the educational practices in promoting selfmanagement in type 2 diabetes mellitus. Rev Esc Enferm USP. 2011; 45(5):243-50.

5. Costa JA, Balga RSM, Alfenas RCG, Cotta RMM. Health promotion and diabetes: discussing the adherence and motivation of diabetics that participate in health programs. Ciênc Saúde Coletiva. 2011; 16(3):187-94.

6. Sousa LB, Torres CA, Pinheiro PNC, Pinheiro AKB. Práticas de educação em saúde no Brasil: a atuação da enfermagem. Rev Enferm UERJ. 2010;18(1):55-60.

7. Gandra FPP, Silva KC, Castro CF, Esteves EA, Nobre LN. The effect of an education program on the knowledge level and attitudes about Diabetes Mellitus. Rev Bras Prom Saúde. 2011; 24(4):32231.

8. Camargo AM, Silva APBV, Wolff LDG, Soares VMN, Gonçalves CGO. Abordagens grupais em saúde coletiva: a visão de usuários e de profissionais de enfermagem. Rev Bras Ciênc Saúde. 2012; 10(31):1-9.

9. Melo MRC, Dantas VLA. Círculos de cultura e promoção da saúde na estratégia de saúde da família. Rev Bras Prom Saúde. 2012; 25(3):32836.

10. Heidmann IBS, Boehs AE, Wosny AM, Stulp KP. Incorporação teórico-conceitual e metodológica do educador Paulo Freire na pesquisa. Rev Bras Enferm. 2010; 63(3):416-20. 
11. Nogueira ALG, Munari DB, Santos LF, Oliveira LMAC, Fortuna CM. Therapeutic factors in a group of health promotion for the elderly. Rev Esc Enferm USP. 2013; 47(6):134-42.

12. Dias GAR, Lopes MMB. Educação e saúde no cotidiano de enfermeiras da atenção primária. Rev Enferm UFSM. 2013; 3(3):449-60.

13. Pereira DA, Costa NMSC, Sousa ALL, Jardim PCBV, Zanini CRO. The effect of educational intervention on the disease knowledge of diabetes mellituspatients. Rev Latino-Am Enfermagem. 2012; 20(3):478-85.

14. Jarvis J, Skinner TC, Carey ME, Davies MJ. How can structured self-management patient education improve outcomes in people with type 2 diabetes? Diabetes Obes Metab. 2010; 12(1):12-9.

15. Figueiredo MFS, Rodrigues Neto JF, Leite MTS. Educação em saúde no contexto da saúde da família na perspectiva do usuário. Interface Comum Saúde Educ. 2012; 16(41):315-29.

16. Funnell MM, Brown TL, Childs BP, Haas L, Hosey $\mathrm{GM}$, Jensen B, et al. National standards for diabetes self-management education. Diabetes Care. 2009; 32(suppl.1):S89-96.
17. Santos AL, Pasquali R, Marcon SS. Sentimentos e vivencias de indivíduos participantes de um grupo de apoio para o controle da obesidade: um estudo qualitativo. On line Braz J Nurs [periódico na Internet]. 2012 [citado 2014 jun 10]; 11(1). Disponível em: http://www.objnursing.uff.br/ index.php/nursing/article/view/3251

18. Ford CD, Kim MJ, Dancey BL. Perceptions of hypertension and contributing personal and environmental factors among rural southern African American women. Ethn Dis. 2009; 19(4):407-13.

19. Monteiro EMLM, Vieira NFC. Educação em saúde a partir de círculos de cultura. Rev Bras Enferm. 2010; 63(3):397-403.

20. Frigo LF, Silva RM, Mattos KM, Boeira GS, Manfi F, Piaia E, et al. Ação educativa interdisciplinar para pacientes com diabetes na atenção básica: uma revisão bibliográfica. Rev Epidemiol Control Infect. 2012; 2(4):141-3. 